Original Article

\title{
EFFECT OF SUCROSE AND MEDIA STRENGTH ON IN VITRO MULTIPLICATION IN SWERTIA CHIRATA BUCH.-HAM EX WALL: AN ENDANGERED MEDICINAL HERB
}

\author{
MANU PANT ${ }^{*}$, PRABHA BISHT ${ }^{* *}$, MANJU P. GUSAIN ${ }^{* * *}$
}

*Department of Life Sciences, Graphic Era (Deemed to be University), 566/6, Bell Road, Clement Town, Dehradun 248002, Uttarakhand, India, ${ }^{* *}$ Tissue Culture Lab, G and TP Division, Forest Research Institute, Dehradun, Uttarakhand, 248006, India, ${ }^{* *}$ Department of Zoology and Biotechnology, HNB Garhwal University, Srinagar Garhwal, Uttarakhand, India Email: himaniab@gmail.com

Received: 26 Jul 2018 Revised and Accepted: 26 Sep 2018

\section{ABSTRACT}

Objective: The present study was performed to investigate the role of varying concentrations of carbohydrate source and strengths of nutrient medium in growth and development of in vitro shoots of Swertia chirata-an endangered medicinal plant.

Methods: MS medium supplemented with 6-Benzylaminopurine $(4.44 \mu \mathrm{M})$, Indole-3 acetic acid $(2.85 \mu \mathrm{M})$ and Adenine sulphate $(271.45 \mu \mathrm{M})$ was used to test the efficiency of of sucrose at concentrations of 1-5\% and of media strength varying from full to one-fourth. The data were analysed using analysis of variance (ANOVA) of Completely Randomized Design (CRD) in GenStat 5 Edition 3.2 for PC/Windows NT (Copyright 1995, Lawes Agricultural Trust (Rothamsted Experimental Station))

Results: Observations on axillary shoot multiplication indicated that sucrose at a concentration of $3 \%$ and MS medium in its full strength proved to be most optimal for in vitro culture multiplication. On this medium combination mean number of 11.80 shoots (after 4 w) and 18.50 shoots (after 8 w) could be obtained On sucrose free medium the shoots exhibited necrosis while at lower concentrations of 1-2\% sucrose, the shoots developed were thin and unsuitable for further growth in vitro. At higher levels of sucrose in the medium, the shoots became thick and stunted. Similarly, reduction in medium strength resulted in a decline in shoot number and shoot length to an average of 6.50 shoots $(1.33 \mathrm{~cm}$ mean length) on half strength medium and 5.60 shoots ( $0.88 \mathrm{~cm}$ mean length) on one-fourth strength; as observed after $4 \mathrm{w}$.

Conclusion: The experimental findings suggest that any decline from the standard had a significant effect on the number, size and overall health of shoots developed in vitro. The conditions so standardized augment the production of healthy shoots that shall aid in subsequent rooting and survival after transplantation of tissue-culture raised plantlets.

Keywords: Swertia chirata, In vitro propagation, Medicinal plant, Shoot length, Shoot multiplication

(C) 2018 The Authors. Published by Innovare Academic Sciences Pvt Ltd. This is an open-access article under the CC BY license (http://creativecommons.org/licenses/by/4.0/] DOI: http://dx.doi.org/10.22159/ijpps.2018v10i11.28135

\section{INTRODUCTION}

Swertia chirata is a native of temperate Himalaya and widely acknowledged as a medicinal herb to cure chronic fever, anaemia, blood, liver, lung and skin disorders [1-4]. The bitter active ingredients of the plant viz. amarogentin, xanthones, iridoid glycosides, mangiferin and C-glucoflavones [5-7] account for its wide range of medicinal and curative powers. The plant, therefore, enjoys a good national and international market. However, Swertia chirata has now been categorized as critically endangered [8-11] owing to unscientific collection practices from the wild; aided by poor seed germination rate in nature (only $2-4 \%$ ) and low seed viability [1214]. Consequently, development of alternative propagation strategies for this important medicinal plant becomes the call of the hour. Some studies have already been performed to develop large-scale propagation protocol for $S$. chirata via tissue culture technology. However, there is a lacuna in studies to standardize different physical parameters involved in the propagation of plant in vitro. The present work was undertaken to investigate the effect of different carbohydrate concentrations and medium strength on in vitro shoot multiplication of $S$. chirata. The findings shall ensure optimal utilization of resources in establishing a standardized system for maximal production of healthy plantlets of Swertia chirata.

\section{MATERIALS AND METHODS}

\section{Chemicals and reagents}

Standard analytical grade chemicals of Merck, India, and Hi-media laboratories, India were used in the present study. The culture media comprised of inorganic salts, organic compounds, amino acids, plant growth regulators, carbohydrate source and gelling agents. All chemicals used for stock preparation were of analytical grade. All major and minor salts components of MS medium used were of Hi-media laboratories, India. Plant growth regulators, adjuvants, sucrose (carbohydrate source), agar (gelling agent) used were also of Hi-media laboratories, India. Auxins, cytokinins used were dissolved in dilute $1.0 \mathrm{~N} \mathrm{NaOH}$ or $1.0 \mathrm{~N} \mathrm{HCl}$.

\section{General methodology}

In vitro cultures established via axillary bud proliferation and multiplying on MS medium containing BAP $(4.44 \mu \mathrm{M})+\mathrm{IAA}(2.85$ $\mu \mathrm{M})+$ Ads $(271.45 \mu \mathrm{M})$ (Pant et al. 2010) were used to assess the effect of varying concentrations of sucrose and media strength on shoot multiplication in Swertia chirata. For the purpose, shoots were separated from established cultures and transferred to MS medium fortified with PGRs and gelled with $0.7 \%$ agar. Sucrose was used as the carbohydrate source at concentrations of $1-5 \%$ in the multiplication medium while MS medium strength was tried at three levels: $(1 / 4 \mathrm{X}, 1 / 2 \mathrm{X}, 1 \mathrm{X})$ to standardize conditions for best results of in vitro multiplication. In all experiments, the $\mathrm{pH}$ of the medium was adjusted to 5.8 prior to autoclaving the medium at $121^{\circ} \mathrm{C}$ and $1.0 \mathrm{x}$ $10^{5} \mathrm{~Pa}$ for $15 \mathrm{~min}$.

\section{Data collection and analysis}

Observations on average shoot number and average shoot length were recorded after an interval of $4 \mathrm{w}$ and $8 \mathrm{w}$. All experiments were repeated thrice. Each treatment consisted of minimum ten replicates. The data were analysed using analysis of variance (ANOVA) of Completely Randomized Design (CRD) in GenStat 5 Edition 3.2 for PC/Windows NT (Copyright 1995, Lawes Agricultural Trust (Rothamsted Experimental Station)). The significance level 
was determined at $5 \%(\mathrm{p}<=0.05), 1 \%(\mathrm{p}<=0.01)$ and $0.1 \%(\mathrm{p}<=$ 0.001 ). Mean values of treatments were compared with Least Significance Difference (LSD). Treatments whose difference was less than LSD were considered to be the same while those with the difference more than LSD were considered to be significantly different.

\section{Culture conditions}

The cultures were incubated in a culture room at $25 \pm 1^{\circ} \mathrm{C}$ temperature and $60-65 \%$ relative humidity under a 16/8 h (light/dark) photoperiod with light supplied by cool-white fluorescent tubes (Philips, India) at an intensity of 2500 lux.

\section{RESULTS AND DISCUSSION}

In the present study, significant differences were observed in all parameters of shoot multiplication in all the treatments tried. Plantlets growing under in vitro conditions have limited accessibility to $\mathrm{CO}_{2}$ inside the vessel [16]. Therefore, sugar is supplemented as a carbon source to maintain an adequate supply of carbon for in vitro multiplication and growth of plant cell, tissue, and organs or whole plantlets. Sucrose is the most commonly used source of carbohydrates, having both metabolic and osmotic functions. It provides the carbon precursors for structural and functional components [17], meets the energy demands for growth and physiological functions, maintains the osmotic potential of cells and water conservation $[16,18]$.

In the present study, sucrose in the medium was found to be indispensable for shoot multiplication. On sucrose-free medium, the in vitro shoots initially multiplied slowly. However, within few weeks, the leaves started becoming pale and eventually necrosed. At lower concentrations of sucrose (1-2\%) an average of 6.90 shoots after $4 \mathrm{w}$ and 10.20-10.50 shoots after $8 \mathrm{w}$ could be obtained [table 1]. The shoots so developed were stunted and an average of only $1.53 \mathrm{~cm}-1.61 \mathrm{~cm}$ shoot length after $4 \mathrm{w}$ and $1.85 \mathrm{~cm}-2.24 \mathrm{~cm}$ after 8 $\mathrm{w}$ was attained [fig. $1 \mathrm{~A}, \mathrm{~B}$ ]. Contrasting to these observations, successful multiplication with $2 \%$ sucrose has been reported in Chinese medicinal plants [19] and Bacopa monniera [20]. Similar observations were also reported in Swertia chirata [21] while working on in vitro propagation using seedling derived shoot tip explants. Plantlets growing on sucrose supplemented media have been known to exhibit reduced photosynthesis, probably due to the presence of sufficient energy source (sugars) for other metabolic activities [22-24]. Thus, a decrease in sucrose levels in the medium could be beneficial for in vitro plantlets. However, in our study absence of sucrose in the multiplication medium hampered in vitro multiplication with shoots becoming dead after a period of $4 \mathrm{w}$. At $1 \%$ sucrose, thin shoots and leaves developed which were not suitable for further sub-culturing while at $2 \%$ concentration the average number of shoots developed and average shoot length was significantly less than the results obtained at $3 \%$ concentration.

A report on bamboo showed that increased level of sucrose at 3-4\% did not affect shoot number but caused albinism [25]. No such observations were made in the present study and sucrose at concentrations $3-4 \%$ produced healthy shoots with the development of normal sized leaves. However, with increased levels of sucrose (5\%) shoots became thick and stunted shoots along with declined multiplication [fig. $1 \mathrm{E}$ ]. Sucrose at $3 \%$ level was found to be the most optimal and essential for the development and growth of shoots [fig. 1C]. On this combination, an average of 11.80 shoots with average shoot length $1.94 \mathrm{~cm}$ after a period of $4 \mathrm{w}$, and 18.50 shoots with average shoot length $2.55 \mathrm{~cm}$ after $8 \mathrm{w}$ was recorded. It has been reported that sucrose supplied at a concentration of $3 \%$ in the medium increases the photosynthetic ability, thereby improving survival of plantlets [26]. The results of the present investigations are also compatible with previous reports in other medicinal plants viz. Gentian kurroo [27], Gentiana sps. [28], Ocimum gratissimum [29], Bacopa monnierri [30], Gentiana scabra [31], Cassia angustifolia [32]. Henceforth, sucrose at $3 \%$ concentration was considered to be most efficient for in vitro shoot multiplication of $S$. chirata. The observations are in corroboration with previous studies on Swertia chirata reporting the efficacy of $3 \%$ sucrose for in vitro multiplication via nodal and shoot tip explants [33-36].
The inorganic salt formulation of MS medium [37] is widely used in plant tissue culture studies for providing basic nutrition to the growing tissues supplemented by plant growth regulators or natural additives for stimulated growth. MS medium is a high salt medium with high levels of nitrogen, potassium and some of the micronutrients, particularly boron and manganese [38]. This high salt content often makes it unsuitable for optimal development of plantlets in vitro; resulting in the need to modify the media strength. In the present study, the effect of media concentrations on in vitro shoot multiplication was studied, and the highly significant difference was observed among the treatments tried [table 2]. It was observed that the best results of shoot multiplication were obtained on full strength MS medium. Reduction of salt strength in the medium resulted in a proportional decline in shoot development. The mean number of shoots multiplied and average length of shoots decreased from $11.80(1.94 \mathrm{~cm})$ in $1 \mathrm{X}$ to $6.50(1.33 \mathrm{~cm})$ in $1 / 2 \mathrm{X}$ and $5.60(0.88 \mathrm{~cm})$ in $1 / 4 \mathrm{X}$ medium after $4 \mathrm{w}$ and from $18.50(2.55 \mathrm{~cm})$ in $1 \mathrm{X}$ to $12.20(1.88 \mathrm{~cm})$ in $1 / 2 \mathrm{X}$ and $9.20(1.23 \mathrm{~cm})$ in $1 / 4 \mathrm{X}$ medium. Thus, MS medium in its full strength was found to be most effective for optimal in vitro shoot multiplication in S. chirata (fig. 2 A, B, C). A direct association between medium strength and the number and length of shoots could be associated with the fact that altering media strength changes the concentration of essential nutrients required for tissue organogenesis.

As a result, the amount of nutrients in culture media also varies for different plant species and genotype and needs to be standardized for protocol development. Our results are in corroboration with previous studies on medicinal plants where full strength MS medium has proven to be efficient for in vitro shoot multiplication $[34,35,39]$.

\section{CONCLUSION}

The present results indicate the importance of maintaining appropriate levels of carbohydrate source and nutrient strength in culture medium used for in vitro propagation of an important and endangered medicinal plant Swertia chirata. Any deviation from the optimal level is suggested to cause a deterioration in healthy shoot development and subsequently hampered in vitro rooting and transplantation.

\section{ABBREVIATION}

Murashige and Skoog's (1962) (MS), 6-Benzylaminopurine (BAP), indole-3 acetic acid (IAA), adenine sulphate (Ads), medium strength (X), plant growth regulator (PGR)

\section{AUTHORS CONTRIBUTIONS}

All the experiments were done by the first author. Second and third author supervised the work, and all authors were involved in designing of the experiment and preparation of the manuscript.

\section{CONFLICT OF INTERESTS}

The authors declare that there is no conflict of interest

\section{REFERENCES}

1. The Wealth of India. A dictionary of indian raw materials and industrial products. Vol. X. Publications and information directorate, CSIR, New Delhi; 1976. p. 77-81.

2. Thakur RS, Puri HS, Hussain A. Major medicinal plants of India, CIMAP, Lucknow, India; 1989. p. 41-3.

3. Joshi SG. Ed. Medicinal Plants. Oxford and IBH, New Delhi; 2000. p. 216.

4. Bhattacharjee SK. Handbook of medicinal plants. Pointer Publishers, Jaipur, India; 2001. p. 69-71.

5. Asthana PK, Sharma NK, Kulshreshtha DK, Chatterjee SK. A xanthone from Swertia chirayita. Phytochemicals 1991; 30:1037-9.

6. Jensen SR, Schripsema J. Chemotaxonomy and pharmacology of gentianaceae. In: Jensen SR, Schripsema J. ed. Gentianaceaesystematics and natural history. Vol. V. Cambridge University Press, Cambridge; 2002. p. 574-631.

7. Mallikarjun N, Mesta SC, Prashith KTR, Sudharshan SJ, Vinayaka KS. Anti mosquito (insecticidal) activity of extracts of Hemidesmus 
indicus and Swertia chirata against Aedes aegypti mosquito larvae-a comparative study. Drug Invention Today 2010;2:106-8.

8. Nayar MP, Shastry ARK. Red data book of indian medicinal plants. Vol. I, II, II. Botanical Survey of India (BSI), Calcutta; 1990.

9. Semwal DP, Saradhi PP, Nautiyal BP, Bhatt AB. Current status, distribution and conservation of rare and endangered medicinal plants of Kedarnath wildlife sanctuary. Central Himalayas, India. Curr Sci 2007;92:1733-8.

10. IUCN, SSC. The IUCN red list of threatened species. 1994-2007 version, Switzerland; 2008.

11. Pradhan BK, Badola HK. Swertia chirayita, a high value endangered medicinal herb: potential in north-east India. Ecotone 2010;2:24-7.

12. Anonymous. Biodiversity Conservation Prioritization Project, conservation assessment and management plan (CAMP) for endemic medicinal plants in India. Central Institue of Medicinal and Aromatic Plants, Lucknow; 1997.

13. Rai LK, Prasad P, Sharma E. Conservation threats to some important medicinal plants of the Sikkim Himalaya. Biol Cons 2000;93:27-33

14. Joshi P, Dhawan V. Swertia chirayita-an overview. Curr Sci 2005;89:635-8.

15. Pant $\mathrm{M}$, Bisht $\mathrm{P}$, Gusain MP. In vitro propagation through axillary bud culture of Swertia chirata Buch.-Ham ex Wall: an endangered medicinal herb. Int J Integr Biol 2010;10:48-53.

16. Hazarika BN. Acclimatization of tissue-cultured plants. Curr Sci 2003;85:1704-12.

17. Marino G, Bertazza G, Magnanini E, Altan AD. Comparative effects of sorbitol and sucrose as main carbon energy sources in micropropagation of apricot. Plant Cell Tissue Organ Cult 1993;34:235-44.

18. Hartmann HD, Kester DE, Davies FT, Geneva RL. Plant propagation: principles and practices. $6^{\text {th }}$ Edition. Prentice-Hall International (UK) Limited, London; 1997.

19. Nalwade SM, Tsay HS. In vitro propagation of some important Chinese medicinal plants and their sustainable usage. In Vitro Cell Dev Biol Plant 2004;40:143-54.

20. Naik PM, Manohar SH, Praveen N, Murthy HN. Effects of sucrose and $\mathrm{pH}$ levels on in vitro shoot regeneration from leaf explants of Bacopa monnieri and accumulation of bacoside a in regenerated shoots. Plant Cell Tiss Org Cult 2010;100:235-9.

21. Balaraju K, Agastian P, Ignacimuthu S. Micropropagation of Swertia chirata Buch.-Hams. ex Wall.: a critically endangered medicinal herb. Acta Physiol Plant 2009;31:487-94.

22. Desjardins $\mathrm{Y}$, Laforge $\mathrm{F}$, Lussier C, Gosselin A. Effect of $\mathrm{CO}_{2}$ enrichment and high photosynthetic photon flux on the development of autotrophy and growth of cultured tissue strawberry, raspberry and asparagus plants. Acta Hortic 1988;230:47-57.

23. Rolland F, Moore B, Sheen J. Sugar sensing and signalling in plants. Plant Cell 2002;14:S185-S205.

24. Amiard V, Mueh KE, Demming-Adams B, Ebbert V, Turgeon R, Adams WW. III Anatomical and photosynthetic acclimation to the light environment in species with different mechanisms of phloem loading. Proc Natl Acad Sci USA 2005;102:12968-173.

25. Saxena S. In vitro propagation of bamboo (Bambusa tulda Roxb.) through shoot proliferation. Plant Cell Rep 1990; 9:431-4.

26. Langford PJ, Wainwright H. Effect of sucrose concentration on the photosynthetic ability of rose shoots in vitro. Ann Bot 1987;60:633-40.

27. Sharma K, Yeung EC, Thorpe TA. Histology of shoot bud ontogeny from seedling root segments of Brassica napus. Ann Bot 1993;71:461-6.

28. Hosokawa K, Nakano M, Oikawa Y, Yamamura S. Adventitious shoot regeneration from leaf, stem and root explants of commercial cultivars of Gentiana. Plant Cell Rep 1996; 15:578-81.

29. Saha S, Kader A, Sengupta C, Ghosh P. In vitro propagation of Ocimum gratissimum L. (Lamiaceae) and its evaluation of genetic fidelity using RAPD marker. Am J Plant Sci 2012; 3:64-74.

30. Kaur J, Nautiyal K, Pant M. In vitro propagation of Bacopa monnieri (L.) wettst-a medicinally priced herb. Int J Curr Microbiol Appl Sci 2013;2:131-8.

31. Huang SH, Agrawal DC, Wu FS, Tsay HS. In vitro propagation of Gentiana scabra bunge-an important medicinal plant in the Chinese system of medicines. Bot Stud 2014;55:56.

32. Siddique I, Bukhari NAW, Perveen K, Siddiqui I. Influence of plant growth regulators on in vitro shoot multiplication and plantlet formation in Cassia angustifolia Vahl. Braz Arch Biol Technol 2015;58:686-91.

33. Ahuja A, Koul S, Kaul BL, Verma NK, Kaul MK, Raina RK, et al. Media compositions for the faster propagation of Swertia chirayita. WO 03/045132 AL; 2003.

34. Joshi P, Dhawan V. Axiliary multiplication of Swertia chirayta (Roxb. Ex Fleming) H Karst. A critically endangered medicinal herb of temperate himalayas. In Vitro Cell Dev Biol Plant 2007;43:631-8.

35. Chaudhuri RK, Pal A, Jha TB. Production of genetically uniform plants from nodal explants of Swertia chirata Buch.-Ham. ex Wall:-an endangered medicinal herb. In Vitro Cell Dev Biol Plant 2007;43:467-72.

36. Koul S, Suri KA, Dutt P, Sambyal M, Ahuja A, Kaul MK Protocol for in vitro regeneration and marker glycoside assessment in Swertia chirata buch-Ham. In: Jain SM, Saxena PK. ed. Methods in molecular biology, protocols for in vitro cultures and secondary metabolite analysis of aromatic and medicinal plants. Vol. 547, Humana Press: New York; 2009. p. 139-53.

37. Murashige T. Plant propagation through tissue culture. Ann Rev Plant Physiol 1974;25:136-66.

38. Cohen D. The culture medium. Acta Hort 1995;393:15-24.

39. Syedy M, Nama KS. In vitro propagation of shoots and callus induction of Gymnema sylvestre $\mathrm{R}$. Br. "an important antidiabetic plant”. Int J Curr Pharm Res 2018;10:60-64. 